\title{
A case report on IgA nephropathy in pregnancy
}

\author{
Nupur Anand*, A. V. Gokhale, Shonali Agarwal
}

Department of Obstetrics and Gynaecology, SSG Hospital, Baroda Medical College, Baroda, Gujarat, India

Received: 24 May 2019

Revised: 27 June 2019

Accepted: 02 July 2019

\section{*Correspondence:}

Dr. Nupur Anand,

E-mail: nupur28@yahoo.co.in

Copyright: (c) the author(s), publisher and licensee Medip Academy. This is an open-access article distributed under the terms of the Creative Commons Attribution Non-Commercial License, which permits unrestricted non-commercial use, distribution, and reproduction in any medium, provided the original work is properly cited.

\begin{abstract}
IgA Nephropathy is a primary glomerular disease leading cause of primary glomerulonephritis and one of the important leading cause of secondary hypertension. Pregnancy causes complex pathological changes in patients with IgA nephropathy affecting the renal function leading to secondary hypertension which in turn affects the prognosis of these patients. The association between chronic kidney disease and increased risk of adverse maternal and fetal outcomes which includes pre-eclampsia, accelerated decline in renal function, intrauterine growth retardation, preterm delivery and fetal death, is well recognised. Management of patients with $\operatorname{IgA}$ Nephropathy in pregnancy is challenging and thus authors are discussing here a case with successful outcome. Our patient was a known case of IgA Nephropathy and landed up with complications during pregnancy which was manged successfully.
\end{abstract}

Keywords: Chronic kidney disease, Hypertension, IgA Nephropathy, Preclampsia, Pregnancy, Preterm Labour

\section{INTRODUCTION}

IgA nephropathy is one of the most commonly diagnosed primary glomular disease and the leading cause of primary glomerulonephritis causing end stage renal disease. It is also one of the leading cause of secondary hypertension due to renal parenchymal disease. IgA nephropathy, also called Berger disease is characterized by $\operatorname{IgA}$ depositions in the glomerular mesangial area. It is associated with symptoms like hematuria and proteinuria, and hypertension.

Chronic kidney disease affects $3.3 \%$ of pregnancies. ${ }^{1}$ $\operatorname{IgA}$ nephropathy is the most common cause of CKD. The global incidence rate of $\operatorname{IgA}$ nephropathy is 2.5 per 100,000 per year. $^{2}$ IgA nephropathy can occur at any age, but there is an increased susceptibility in men in their 2nd and 3rd decade. Pregnancy causes complex pathological changes in patients with $\operatorname{IgA}$ nephropathy affecting the renal function leading to secondary hypertension which in turn affects the prognosis of these patients.

The association between chronic kidney disease and increased risk of adverse maternal and fetal outcomes which includes pre-eclampsia, accelerated decline in renal function, intrauterine growth retardation, preterm delivery and fetal death, is well recognised. ${ }^{3}$

It was estimated that incidence of preterm delivery was increased from $24 \%$ in stage $1 \mathrm{CKD}$ to $89 \%$ in stages 4 and 5 CKD4. Perinatal mortality was found to be $33 \%$ in women with hypertension as compared to $1 \%$ in normotensive women and $14 \%$ in women with impaired renal parameters as compared to $3 \%$ in women with normal renal function. Other complications included spontaneous abortion, $8 \%$ small for gestational age, $4 \%$; and perinatal death, $16 \% .{ }^{4}$ Management of patients with $\operatorname{Ig}$ A Nephropathy in pregnancy is challenging and thus authors are discussing here a case with successful outcome. 


\section{CASE REPORT}

A 34 year third gravida presented to our OPD on 20/8/18 with 20 weeks 6 days of ammenorhea. She had two uneventful and successful fullterm pregnancies in the past. She was a known case of $\operatorname{IgA}$ nephropathy recently diagnosed just before conception and on treatment. She was taking treatment from Institute of kidney diseases, civil hospital, Ahmedabad.
She had presented in our OPD with amenorrhea of five months and was diagnosed in having pregnancy of 20 weeks 6 days. On examination her BP was-140/90 mm of Hg, PR-88/min, Pedal edema was present. On per abdomen examination her uterus was 20 weeks size which coincided with her LMP, external ballotment was present and fetal movements were perceived. Her usg was done which had fetal parameters of 20 weeks, liquor adequate, no congenital anomalies detected. Her routine investigations were sent results are shown in Table 1.

Table 1: investigations.

\begin{tabular}{|lllll|}
\hline & $27-02-2018$ & $20-08-2018$ & $01-10-2018$ & $19-11-2018$ \\
\hline & pre-pregnancy & 1 st ANC Visit & subsequent antenatal visits & Intrapartum \\
\hline $\mathrm{Hb}(\mathrm{g} / \mathrm{dl})$ & 11.8 & 12.1 & 12.6 & 11.2 \\
\hline $\mathrm{Wbc} /(\mathrm{cumm})$ & 7050 & 8400 & 8100 & 8340 \\
\hline urea $(\mathrm{mg} / \mathrm{dl})$ & 44 & 23 & 30 & 27 \\
\hline Creatinine(mg/dl) & 1.4 & 0.6 & 0.5 & 0.7 \\
\hline $\mathrm{SGPT}(\mathrm{U} / \mathrm{L})$ & 15 & 17 & 20 & 27 \\
\hline SGOT(U/L) & 31 & 23 & 30 & 136 \\
\hline Serum electrolytes(mmol/L) & & & & 4 \\
\hline sodium & 134 & 136 & 134 & 106 \\
\hline potassium & 4.6 & 3.6 & 3.9 & 0.8 \\
\hline chloride & 104 & 0.8 & 103 & 0.4 \\
\hline serum bilirubin(mg/dl) & 0.7 & 0.4 & 0.9 & 0.4 \\
\hline direct(mg/dl) & 0.4 & 0.4 & 0.5 & Normal \\
\hline indirect(mg/dl) & 0.3 & Normal & 0.4 & Normal \\
\hline urine routine micro & $2-3 \mathrm{RBCS}$ & &
\end{tabular}

Pre-pregnancy Pt was first admitted in Ahmedabad on 27/2/18 with anasarca. At the time of admission she had complaint of headache and edema in whole body. her BP was 180/90 mm of $\mathrm{Hg} \mathrm{Pt}$ was suspected of nephrotic syndrome at that time but when she did not improve with medical treatment, renal biopsy was taken. Renal biopsy was suggestive of IgA Nephropathy (mesangio proliferative glomerulonephritis- oxford classification=M1E0S0T0L0). At that time based on renal biopsy treatment was started on $\mathrm{T}$. Atorvastatin $40 \mathrm{mg}$ od, T Telmisartan $40 \mathrm{mg}$ od, T Torsemide $40 \mathrm{mg}$ od, $\mathrm{T}$ prednisolone $60 \mathrm{mg}$ od, $\mathrm{T}$ calcium $500 \mathrm{mg}$ bd and $\mathrm{Inj}$ Lasix $40 \mathrm{mg} 8 \mathrm{hrly}$. Pt was discharged after 10 days.

Pt conceived in March; her LMP was 21/3/18 but she did not know about her pregnancy and thus continued the same medications.

Pt came to us in OPD for treatment of amennorhea on 20/8/18 and was found to be pregnant after which she as advised to go to her nephrologist for change of treatment .Investigations were sent and an Ultrasound was done which was suggestive of oligohydromnias, no congenital anomaly was detected.
She was advised by her nephrologist to stop telmisartan and asked to start labetalol $100 \mathrm{mg}$ bd and decrease dose of T prednisolone to $30 \mathrm{mg} 1 \mathrm{od}$. She was also counselled about her condition and its influence in the outcome of pregnancy.

Subsequently she took regular ANC visits at our hospital for BP monitoring, fetal surveillance and screening of complications. She was asked to continue the same treatment.

Pt came to labour room on 19/11/18 with premature labour pains . at time of admission her Blood presuure was $150 / 90 \mathrm{~mm}$ of $\mathrm{Hg}$, Pulse rate= $92 / \mathrm{min}$, pedal edema present. Her investigations were sent(Table 1). Intrapartum period was uneventful and she delivered a Preterm appropriate for gestational age male of $1505 \mathrm{gm}$ on 20/11/18 at 10:12 am. Newborn was admitted in NICU for prematurity.

Postpartum patient was started on T Prednisolone 30mg, $\mathrm{T}$ telmisartan $40 \mathrm{mg}$ od and $\mathrm{T}$ Vasta $10 \mathrm{mg}$ HS. Her Blood pressure was $140 / 90 \mathrm{~mm}$ of $\mathrm{Hg}$. The newborn was admitted for 20 days and was then handed over to mother once adequate weight was gained. She was discharged 
one month after delivery with advise to have follow up with her nephrologist and use contraception like barrier methods and progesterone only pills after 6 weeks.

\section{DISCUSSION}

Management of pregnancy induced complications in patients with IgA nephropathy is difficult and challenging as it affects both mother and fetus adversely. The disease is rare and mimics a number of diseases occurring in pregnancy. Our patient discussed above had anasarca and high BP before pregnancy and was suspected to be having nephrotic syndrome based on symptoms. When she did not respond to the medical treatment decision of renal biopsy was taken which was suggestive of IgA nephropathy. She started treatment immediately and her symptoms were relieved. Once she conceived, she did not go for follow up and continued the same medications. Her pregnancy was complicated by preeclampsia and preterm labour.

Clinical parameters used to determine the prognosis of IgA nephropathy are the level of proteinuria, hypertension and serum creatinine, and the pathological indicators are the presence of glomerular sclerosis, interstitial renal tubular injury, vascular lesions. ${ }^{5}$

According to various studies deterioration of renal function was more common in males. ${ }^{6}$ It was also found that Pregnancy in patients with $\operatorname{IgA}$ Nephropathy with preserved renal function did not accelerate deterioration of renal function. But pregnant women with $\operatorname{Ig} \mathrm{A}$ Nephropathy were at higher risk of pregnancy complications even when renal functions were normal. ${ }^{7}$ In our patient renal function was preserved as she was diagnosed pre pregnancy and started treatment but due to loss in follow up she was affected by pre-eclampsia and preterm delivery. This shows the importance of pre pregnancy diagnosis, evaluation and counselling and regular followup during antenatal care. Many Cases of IgA nephropathy can exist subclinically without any symptoms and therefore will only be diagnosed through routine urinary tests or can present with severe symptoms as in our case. ${ }^{2}$

Frequent blood pressure monitoring during antenatal care is very important to decrease risk of adverse fetal and maternal outcomes. Blood pressure guidelines suggest that for PIH patients antihypertensive drugs are indicated when systolic BP is above 150 and diastolic above 100 $\mathrm{mm}$ of $\mathrm{Hg}$. But in Patients with chronic hypertension there is risk of damage to their target organs and they are more susceptible to organ dysfunction and preeclampsia during and after pregnancy, even if all the functional values are within the normal range. Therefore, lower threshold values of $140 / 90 \mathrm{~mm} \mathrm{Hg}$ is required for these patients with chronic hypertension. ${ }^{8}$ The aim for the management of the blood pressure in patients complicated by hypertension due to renal disease is to minimize any damage to target organs while maintaining blood perfusion to the placenta.

Prednisolone is considered to be relatively safe in pregnancy, and benefits of continuation

outweigh any risk. For the management of hypertension in pregnancy drugs preferred are methyldopa, labetalol, hydralazine, and long-acting nifedipine. Diuretics are often avoided due to the theoretical concern of intravascular contraction but can be used in selected women. ${ }^{4}$

Therefore patients with IgA nephropathy will usually tolerate pregnancy well and will not have an adverse effect, if blood pressure is normal and GFR more than 70 $\mathrm{ml} / \mathrm{min}$ before conception. But in cases with hypertension present preconceptionally as in our case, the rate of live birth is low if hypertension exists before pregnancy and/or is not controlled during gestation. ${ }^{9}$

\section{CONCLUSION}

During pregnancy the pathophysiological changes in patients with $\operatorname{IgA}$ nephropathy causes complications and variable pregnancy outcomes. A number of factors affect the prognosis of patient and outcome of pregnancy like renal function, blood pressure, urine protein levels, and the pathology of the renal tissue.

Thus, prepregnancy diagnosis and treatment is essential to prevent maternal and fetal adverse outcomes. And during pregnancy frequent antenatal visits, BP monitoring and early diagnosis of developing complications helps us in improving pregnancy outcomes.

\section{ACKNOWLEDGMENTS}

It is of utmost importance to express my sense of gratitude to my professors, seniors and colleagues who guided me through this work.

\section{Funding: No funding sources Conflict of interest: None declared Ethical approval: Not required}

\section{REFERENCES}

1. Fitzpatrick A, Mohammadi F, Jesudason S. Managing pregnancy in chronic kidney disease: improving outcomes for mother and baby. Int $\mathbf{J}$ Womens Health. 2016;8:273-85.

2. McGrogan A, Franssen CFM, de Vries CS. The incidence of primary glomerulonephritis worldwide: a systematic review of the literature. Nephrol Dial Transplant. 2011;26(2):414-30.

3. Nevis IF, Reitsma A, Dominic A, McDonald S, Thabane L, Akl EA et al. Pregnancy Outcomes in Women with Chronic Kidney Disease: A Systematic 
Review. Clin J Am Soc Nephrol. 2011;6(11):258798.

4. Blom K, Odutayo A, Bramham K, Hladunewich MA. Pregnancy and glomerular disease: A systematic review of the literature with management guidelines. Clin J Am Soc Nephrol. 2017;12(11):1862-72.

5. Goto M, Wakai K, Kawamura T, Ando M, Endoh M, Tomino Y. A scoring system to predict renal outcome in IgA nephropathy: a nationwide 10-year prospective cohort study. Nephrol Dial Transplant. 2009;24(10):3068-74.

6. Riispere Ž, Laurinavičius A, Kuudeberg A, Seppet E, Sepp K, Ilmoja $M$ et al. IgA nephropathy clinicopathologic study following the Oxford classification: Progression peculiarities and genderrelated differences. Medicina (B Aires). 2016;52(6):340-8.
7. Liu Y, Ma X, Zheng J, Liu X, Yan T. A Systematic Review and Meta-Analysis of Kidney and Pregnancy Outcomes in IgA Nephropathy. Am J Nephrol. 2016;44(3):187-93.

8. Chronic hypertension - Nice Pathways. https://pathways.nice.org.uk/pathways/hypertensioninpregnancy/preeclampsia\#path=view\%3A/pathways /hypertension-in-pregnancy/chronichypertension. $x m l \&$ content=view-node $\% 3$ Anodestreatment-and-diet. Accessed 23 April 2019.

9. Abe S. Pregnancy in IgA nephropathy. Kidney international. 1991 Dec 1;40(6):1098-102.

Cite this article as: Anand N, Gokhale AV, Agarwal S. A case report on IgA nephropathy in pregnancy. Int J Reprod Contracept Obstet Gynecol 2019;8:3402-5. 